\title{
Ants Fail to Add Numbers of Same Elements Seen Consecutively
}

\author{
Marie-Claire Cammaerts ${ }^{1} \&$ Roger Cammaerts ${ }^{2}$ \\ ${ }^{1}$ Biology of Organisms Department, University of Brussels, Belgium \\ ${ }^{2}$ Natural and Agricultural Environmental Studies Department (DEMNA) of the Walloon Region, Belgium \\ Correspondence: Marie-Claire Cammaerts, Independent Researcher, 27, Square du Castel Fleuri, 1170 Bruxelles, \\ Belgium. Tel: 32-2-673-4969. E-mail: mtricot@ulb.ac.be; mccammaerts@gmail.com
}

Received: May 25, 2019

doi:10.5539/ijb.v11n3p37
Accepted: June 5, 2019

Online Published: June 10, 2019

\begin{abstract}
The workers of the ant Myrmica sabuleti have been shown to be able to distinguish different numbers of elements and to be able to add them if seen side by side, at the same time. They have thus a concrete concept of numbers and of adding. It remained to know if they have an abstract mathematical concept of numbers and of their addition. For tempting answering this question, we presented, to M. sabuleti workers, two numbers of elements (circles) not placed side by side but making an angle, the ants having thus to move for seeing the one then the other of the numbers of elements. After 3, 6, 9 and 12 of such training days, the ants were tested in front of the two numbers of elements as well as of their correct sum and their sum plus one element. The ants responded essentially to the two numbers of elements they saw during training, and far less to their sum and sum plus one element. The ants have thus a basic, concrete concept of adding numbers of elements they see. Young human children ( 3 to 6 years old) have such a concrete concept of numbers and of adding, but they acquire in several months, through learning, an abstract mathematical concept of these notions and of related ones.
\end{abstract}

Keywords: Arithmetic, Cognition, Myrmica sabuleti, Operant Conditioning, Training

\section{Introduction}

The notion of numbers, the ability of adding numbers, and the notion of zero are detained by some evolved animal species (and are thus acquired in the course of the animals' evolution), and are acquired by human beings in the course of their life, normally from about three to eight years old (Fuson, 1988). Working on ants, we have shown that these insects can distinguish different numbers of elements (Cammaerts, 2008), have a basic, concrete notion of zero (i.e. of nothing) (Cammaerts \& Cammaerts, 2019a, b), and can add different numbers of identical elements seen at the same time side by side (Cammaerts \& Cammaerts, 2019c). Human children are learned to add numbers of elements firstly by seeing them at a time, all together, side by side, generally under a presentation helping them to learn adding and subtracting, and secondly, about 6 to 12 months later, not seeing them under such a presentation and ultimately without seeing them (and in general learning then also the multiplication table). After having found that the workers of the ant Myrmica sabuleti Meinert 1861 can add numbers of elements seen simultaneously (Cammaerts \& Cammaerts, 2019c), we wondered if they might have accessed to the following step, i.e. might be able to add numbers of elements not seen at the same time side by side, but seen at different times, e.g. consecutively. Since this new research continues the previous one, we worked on the same species using a similar experimental protocol. Before explaining again, but briefly, this protocol and relating our results, we give an insight of what is known about the subject in other animal species.

Experiments on fishes have revealed that these animals are able to discriminate different amounts or numbers of elements, but at a concrete level, i.e. seeing these amounts or numbers (Agrillo, Dadda, Serena, \& Bisazza, 2009; Agrillo, Miletto Petrazzini, \& Bisazza, 2017). They were not asked to add numbers of elements. They can thus be considered, at least until novel tests will be made on them, as being at the first concrete level of the concept of numbers (and therefore maybe of the ability of adding). Amphibians are also at such a first level of the concepts of numbers and adding (Hoag, 2003). Several bird species show ability in evaluating quantities and in counting elements (Pepperberg, 2006). Robins (Garland \& Low, 2014) as well as newborn chicks (Rugani, Vallortigara, Priftis, \& Regolin, 2015) have shown the ability of adding, subtracting or at least counting, presenting then ethological and physiological characteristics analogous to those of humans. Indeed, experiments made on corvid songbirds revealed that, when learned to count, a precise part of their brain is activated, just like is activated a 
precise part of humans' brain while counting (Ditz \& Nieder, 2015, 2016). The authors concluded that their results suggest that crows were judging numerosity. Birds might thus be able to acquire, after having been learned, a concept of number or more precisely of numerosity they can retained without longer seeing the concrete numbers of elements. Such a true counting of elements could also be an ability of some monkeys. Indeed, in a chapter of a book on numerical cognition, Beran, Perdue and Evans (2015) explain that "monkeys can count though having this ability at a limited extent, can estimate ordered magnitudes, and can learn to associate symbols with numbers of items though larger numbers are represented less and less precisely". Monkeys might thus be able to add numbers of items no longer seen, but such a competence has not yet been experimentally confirmed. As for the invertebrates, experiments made on spiders, deprived of some of their prey larders, suggest that these animals may be able to assess the number of preys lacking, and might thus have some numerosity concept (Rodriguez, Briceno, Briceno-Aguilar, \& Höbel, 2015), what allows presuming some potential ability in adding and subtracting elements. As for social hymenoptera, bees have been reported to be able to learn adding as well as subtracting one element (blue as well as yellow respectively) to or from 1-5 presented ones (Howard, Avarguès-Weber, Garcia, Greentree, \& Dyer, 2019). Being rewarded when giving the correct response (i.e. through classical conditioning), the bees 'learned' to add 1 to a number of elements when the elements were blue, or to subtract 1 from a number of elements when the elements were yellow. Concerning the ants, it remained to examine if they could add numbers of elements not seen simultaneously, in order to know if they have more than a concrete concept of numerosity.

\section{Material and Methods}

\subsection{Collection and Maintenance of Ants}

The experiments were performed on eight colonies of M. sabuleti (labeled A to H) collected in June 2018 in an abandoned quarry at Marchin (Condroz, Belgium), as well as in September 2018, also in an abandoned quarry, located in the Aise valley (Ardenne, Belgium). Each colony contained a queen, brood and about 500 workers. Each one was maintained in the laboratory in two to three glass tubes half filled with water, a cotton plug separating the ants from the water. The nest tubes of each colony were set in a tray $(34 \mathrm{~cm} \times 23 \mathrm{~cm} \times 4 \mathrm{~cm})$ which served as foraging area. Pieces of Tenebrio molitor larvae (Linnaeus, 1758) were deposited three times per week in these trays, and small tubes filled with sugar water and plugged with cotton were permanently set in these trays. The ambient temperature was $c a 20^{\circ} \mathrm{C}$, the humidity $80 \%$, the lighting 330 lux while working on ants, and the electromagnetism $2 \mu \mathrm{Wm}^{2}$. These environmental conditions are optimum for the species.
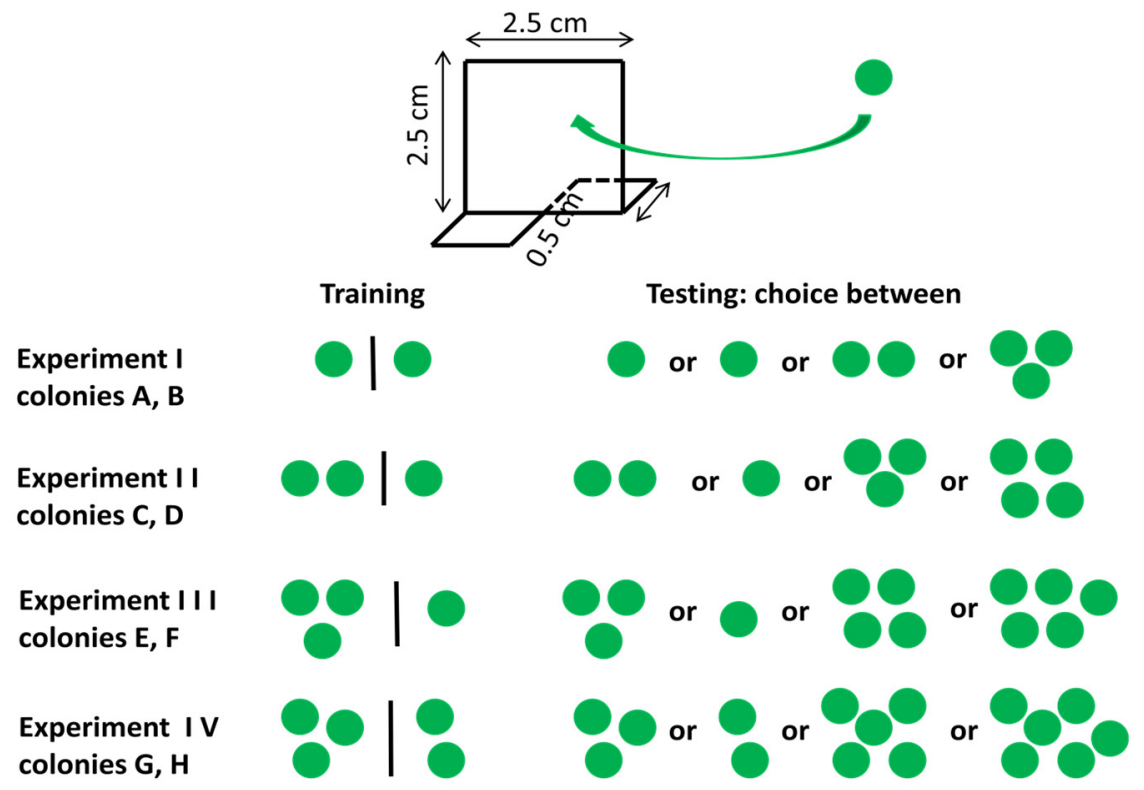

Figure 1. Numbers of elements presented, as shown in Figure 2, to the ants for examining if they could add such presented numbers

The presentation of these elements to the ants, during training and during testing, is schematically explained in Figure 2. Photos of such presentations and of reacting ants are given in Figure 3. 

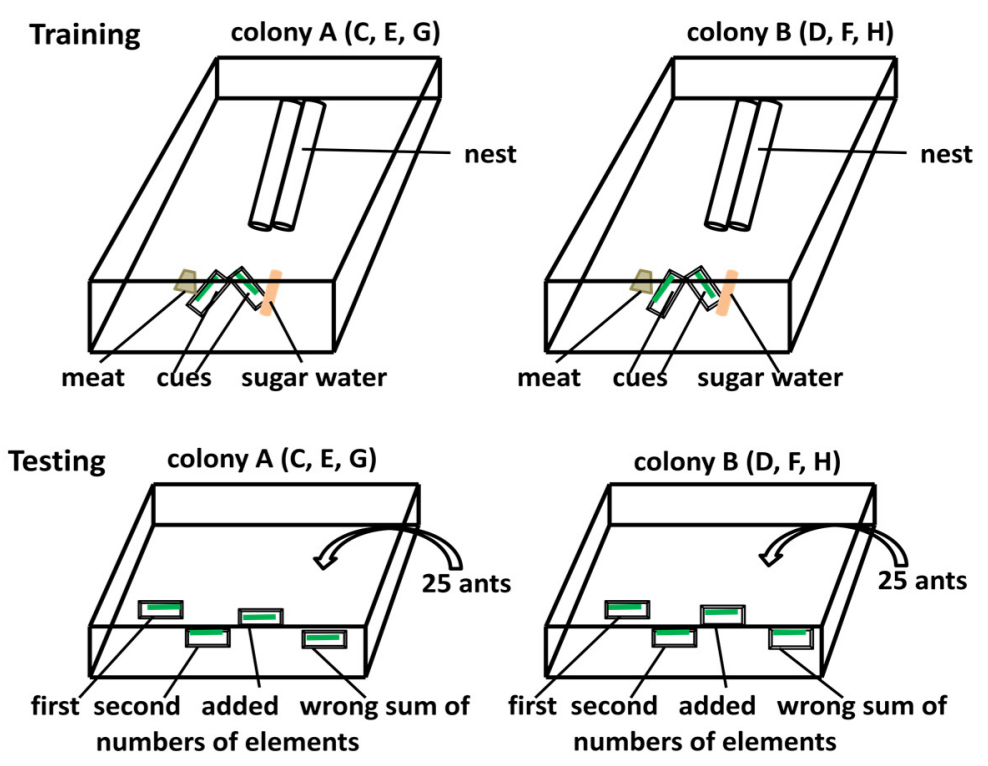

Figure 2. Schematic representation of ants' training (upper part of the schema) and testing (lower part of the schema) to examine if the ants could add numbers never seen side by side

The elements and the numbers used are schematically described in Figure 1; photos of the ants' training and testing are given in Figure 3. During training, the two stands bearing the numbers of elements (here schematized by a green line) were oriented so that the ants could not see these numbers side by side at the same time, but only consecutively.

\subsection{Cues Presented to the Ants}

The cues presented to the ants were different numbers of green circles (diameter: $0.5 \mathrm{~cm}$ ) drawn using Power Point ( $)$ software. Each of these sets of numbers of green circles was tied to a stand $(2.5 \mathrm{~cm} \times 2.5 \mathrm{~cm})$ made of strong white paper (Steinbach $\mathbb{R})$ and maintained vertically thanks to its duly folded horizontal base $(2.5 \mathrm{~cm} \times 0.5 \mathrm{~cm})$ (Figure 1 upper part). The number of elements (i.e. circles) presented on a stand differed according to the experiment (I to IV; Figure 1 lower part). During the training part of each experiment, two stands with their elements were presented to the ants near their food, one turned towards the meat, the other turned to the opposite direction towards the tube containing sugar water (Figure 2, upper part). The two presented stands supported each 1 and 1 element during experiment I; 2 and 1 elements during experiment II; 3 and 1 elements during experiment III; and 3 and 2 elements during experiment IV (Figure 1, lower part). During the testing part of the experiments, four stands were presented to the ants: two stands supported the two numbers of elements presented during training, and the two others supported the sum of these numbers and their sum plus one element (Figure 1, lower part).

\subsection{Experimental Design}

Experiment I was conducted on colonies A and B, experiment II on colonies $\mathrm{C}$ and $\mathrm{D}$, experiment III on colonies $\mathrm{E}$ and $\mathrm{F}$, and experiment IV on colonies $\mathrm{G}$ and $\mathrm{H}$. Each time, the two stands with their elements were deposited, at the same time, between the ants' meat and the sugar water tube (i.e. their food $=$ the reward), the face bearing the elements turned at about $45^{\circ}$ towards the food (Figure 2, upper part; Figure 3, photos on the left). Such a layout of the two stands prevented the ants to see the two numbers simultaneously while eating. The angle made by the back of the stands equaled about $90^{\circ}$; that made by the front of the stands (bearing the elements) equaled about $270^{\circ}$. The ants saw thus the two numbers of elements consecutively, in any order, at any time, and never side by side. This presentation of the stands to the ants constituted the ants' training, which lasted 12 days.

At training days 3, 6, 9 and 12, the ants of each colony were tested in a tray $(30 \mathrm{~cm} \times 15 \mathrm{~cm} \times 4 \mathrm{~cm})$ the borders of which having been slightly covered with talc to prevent escaping, and into which the four stands devoted to testing had been displayed (Figure 2, lower part). These four stands bore the two kinds of numbers presented during training, their sum, and their sum plus one element. They thus bore for experiments I, II, III, and IV respectively: 1, $1,2,3 ; 2,1,3,4 ; 3,1,4,5 ; 3,2,5,6$ elements (Figure 1, lower part). 


\section{Experiment I}

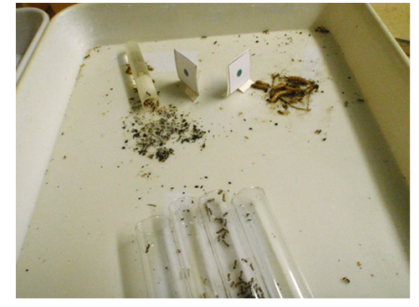

Training

24 hours after removal of the cues

\section{Experiment II}

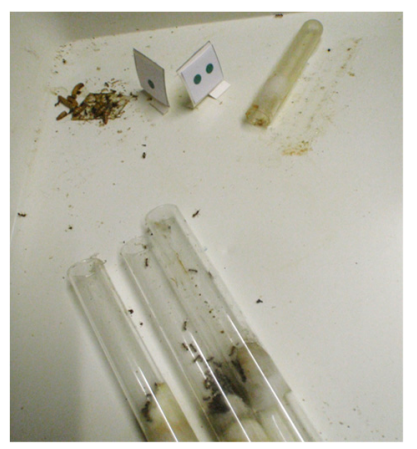

24 hours after removal of the cues

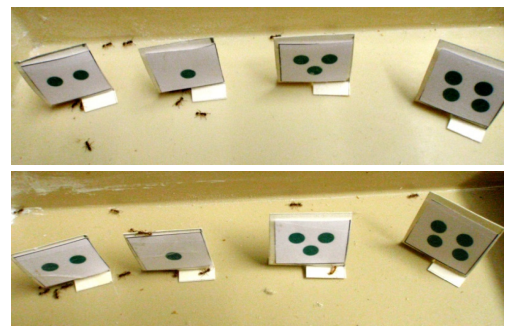

Training

\section{Experiment III}

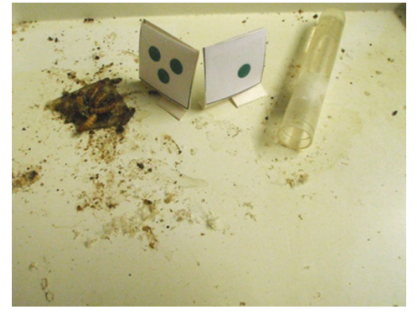

24 hours after removal of the cues
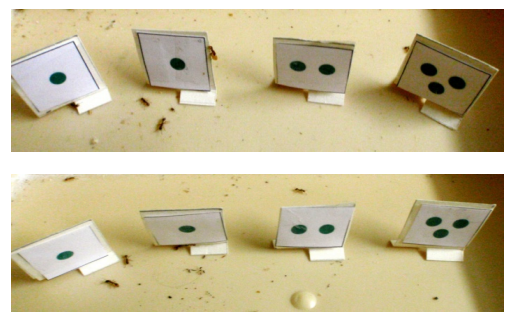

Testing

Testing

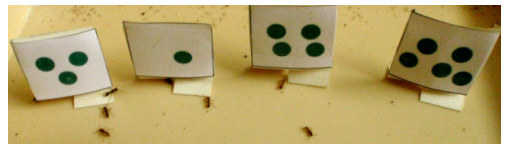

Training

Experiment IV

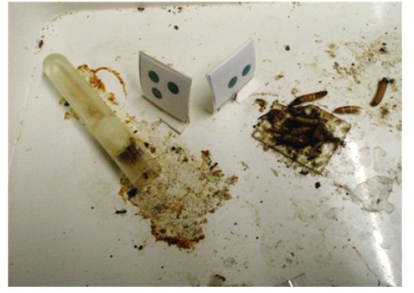

24 hours after removal of the cues

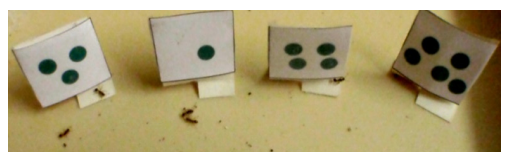

Training

Figure 3. Some photos of the experiments

During training, the ants could see two numbers of elements ( 1 and 1 for experiment I, 2 and 1 for experiment II, 3 and 1 for experiment III, 3 and 2 for experiment IV), but not exactly at the same time, and never side by side. During testing, the ants essentially responded to the two numbers seen during training, and less to their sum ( 2 for experiment I, 3 for experiment II, 4 for experiment III, and 5 for experiment IV). Ants failed thus in adding numbers they never saw side by side. However, 24 hours after the removal of the cues, they remembered the two numbers they saw while being trained. 


\subsection{Experimental Protocol}

During training, each day, for each colony, the ants present near the two stands were counted six times over the day, and the mean value was established (Tables 1 to 4, upper part). At the end of the training, for each experiment, the overall mean number of ants counted for the two colonies was established (value given in the text only).

For making a test (four tests being made for each experiment, at days 3, 6, 9 and 12), 25 ants of each two colonies were transferred into their tray devoted to testing (Figure 2, lower part), and the ants present at a distance of $0-2 \mathrm{~cm}$ from each of the four presented stands (the two stands bearing the numbers presented during training, the stand with the correct sum, and the stand with the sum + one more element) were counted 20 times over 10 experimental minutes. The means of these counts were then established (Tables 1 to 4 , lower part). The numbers (or the means of these numbers) of ants responding to each kind of stand allowed establishing the proportion of responses given to each kind of numbers (for experiments I to IV) during the test made at days 3, 6, 9 and 12. This revealed any possible evolution of the ants' response in the course of their 12 training days. Such an analysis is reported only in the text and not in a table. The numbers of ants counted near each kind of stand during the four testing sessions were totalized, what allowed calculating, for each experiment (I to IV), the percentage of responses given to the two numbers of elements seen during training (and to these two numbers taken all together) as well as to their sum and their sum plus 1 element (and to the two latter sums taken all together). These percentages are presented in Figure 4.

At day 12, after the last test, the two stands displayed on the ants' foraging area near the food were removed and the ants tested 24 hours later for assessing their remembering of the two numbers and/or of their addition, if any, a complementary experiment reported only in the text and not in a table.

\subsection{Statistical Analysis}

The data recorded during the ants' training required no statistical analysis.

Those concerning the ants' testing (i.e. their responses to the four presented numbers of elements) were twice statistically analyzed. For making the first analysis, the 20 numbers of ants counted for each presented number of elements were chronologically arranged and added by four, and the five sums so obtained (not written in the tables but given in the text) for each stand could be compared to one another using the non parametric test of Wilcoxon (Siegel \& Castellan, 1989). The second statistical analysis was made on the totality of the obtained mean values (see the above subsection 2.4., the second alinea). The eight mean values (two colonies $\times 4$ testing sessions $=8$ values) obtained for each of the four numbers of elements presented were compared to one another using the non-parametric test of Wilcoxon (Siegel \& Castellan, 1989).

\section{Results}

\subsection{Experiment I, on Colonies A and B; Training to 1 and 1 Element; Testing to 1, 1, 2 and 3 Elements}

Numerical results are given in Table 1. During training, the ants were rather numerous all around the two presented stands. They meanly were 6.3 in doing so, and could thus sufficiently see the two presented numbers of elements, as they did with numbers presented side by side (Cammaerts \& Cammaerts, 2019c).

After three training days, the ants tended to come essentially near the stands bearing 1 element (Figure 3, Experiment 1). The numbers of ants counted in front of these two stands equaled 40 and 46 , and summed by four were $7,8,7,8,10$ and $9,7,8,11,11$. Those counted in front of the stands bearing 2 and 3 elements equaled 20 and 19 , and summed by four were $4,5,5,4,2$ and $6,4,2,4,3$. The smallest difference to be statistically analyzed was that between the stand with 1 element located on the left and that with 2 elements, and it was significant $(\mathrm{N}=5$, $\mathrm{T}=15, \mathrm{P}=0.031$ ). The ants were thus more present near the stands with 1 element than near those with 2 and 3 elements. After six training days, the ants again responded more to the two numbers seen during training than to their correct and their wrong sums. Summed by four over the experimental time, the numbers of ants counted in front of the stands with 1, 1, 2 and 3 elements equaled 9, 9, 20, 15, 13;21, 14, 15, 10, 12; 7, 8, 4, 2, 6; 3, 1, 2, 3, 5 respectively. The smallest difference to be analyzed was thus between the ants having responded to the stand with 1 element located on the left and that bearing 2 elements, and this smallest difference was significant $(\mathrm{N}=5$, $\mathrm{T}=15, \mathrm{P}=0.031$ ). The ants reacted thus mostly to 1 element. At day 9 , the ants were not inclined to go near the stand bearing the correct sum of 2 elements, but went preferentially near the stands with 1 element. Summed by four over the experimental time, the numbers of ants counted in front of 1, 1, 2 and 3 elements equaled 8, 8, 6, 6, $12 ; 22,26,23,21,23 ; 8,12,3,5,4 ; 5,6,2,3,4$. The difference between the ants' response to the stand with 1 element located on the left and that to the stand with 2 elements was not significant $(\mathrm{N}=4, \mathrm{~T}=-3,+7, \mathrm{P}=0.313)$, but that between the ants' response to the stand with 1 element located on the right and that to the stand with 2 elements was very large (115 vs 32$)$ and significant $(\mathrm{N}=5, \mathrm{~T}=15, \mathrm{P}=0.031)$. The lower presence of ants near the 
stand with 1 element located on the left was due to the pronounced presence of ants in front of the stand laying just aside and bearing 1 element. As a matter of fact, the ants did not mostly react to the correct sum of 2 elements, but essentially to 1 element. At day 12, the ants were again more numerous near the stands bearing 1 element than near the other stands. Summed by four over the experimental time, the numbers of ants recorded for 1, 1, 2 and 3 elements equaled $12,14,14,10,8 ; 20,21,21,14,14 ; 8,8,6,4,4 ; 1,1,2,2,4$ respectively. The smallest difference to be statistically analyzed was that between the numbers of ants recorded for the 1 element located on the left and the numbers recorded for 2 elements, and this difference was significant $(\mathrm{N}=5, \mathrm{~T}=15, \mathrm{P}=0.031)$. Thus, the ants preferentially went to the stands bearing 1 element and less responded to 2 or 3 elements.

The proportions of ants having reacted to $1,1,2$ and 3 elements equaled at day $3: 31.3 \%, 35.9 \%$ (total $=66 \%$ ), $17.2 \%, 15.6 \%$; at day $6: 35.8 \%, 40.2 \%$ (total $=76 \%$ ), $15.2 \%, 8.7 \%$; at day $9: 19.8 \%, 54.7 \%$ (total $=74 \%$ ), $15.1 \%$, $10.4 \%$; and at day $12: 30.9 \%, 47.8 \%$ (total $=78.7 \%$ ), $16.0 \%, 5.3 \%$. Consequently, the ants' tendency to react more to the two numbers seen during training than to the correct sum of these two numbers somewhat increased (from $66 \%$ to $78.7 \%$ ) in the course of the ants' training time.

Concerning the overall statistical significance of the experiment, the eight mean values obtained (Table 1) for the two numbers seen during training were higher than the eight mean values obtained for their correct sum (2) and their wrong one (3) $(\mathrm{N}=8, \mathrm{~T}=36, \mathrm{P}=0.004)$. The ants have thus responded to the two numbers seen consecutively and not to their sum.

Twenty-four hours after having removed the two stands from the ants' foraging area, the ants still responded essentially to the stands bearing 1 element (i.e. to the two numbers they saw during training). The mean numbers of ants obtained for 1, 1, 2 and 3 elements were for colony A 1.7, 1.6, 0.7, 0.7 and for colony B 1.1, 1.6, 0.4, 0.1. Summed by four over the experimental time, the counted numbers for the two colonies, for 1, 1, 2 and 3 elements equaled $11,10,10,13,10 ; 14,15,13,13,9 ; 3,7,7,4,0 ;$ and $0,2,5,4,3$ respectively. The smallest difference to be statistically examined was that between the ants' response to the 1 element located on the left and that to 2 elements, and this smallest difference was significant $(\mathrm{N}=5, \mathrm{~T}=15, \mathrm{P}=0.031)$. Consequently, the ants responded to (and thus memorized) the elements seen during training. This recalled what occurred in the course of the study on the ants' ability in adding numbers of elements seen simultaneously (Cammaerts \& Cammaerts, 2019c) after the removal of the two stands used for training: the ants responded essentially to the numbers of elements seen during training.

Table 1. Results of experiment I conducted on colonies A and B for examining if ants could add $1+1$ elements never seen side by side

\begin{tabular}{|c|c|c|c|c|c|c|c|c|c|c|c|c|c|c|c|c|}
\hline Training & \multicolumn{16}{|c|}{ Mean of 6 daily counts of the ants present near the two presented numbers of elements } \\
\hline days & 1 & & 2 & 3 & 4 & & 5 & 6 & 7 & $\varepsilon$ & & 9 & 10 & 11 & & 12 \\
\hline colony A & 6.5 & & 8.3 & 6.3 & 10.5 & & .7 & 9.5 & 6.3 & 6 & & 7.8 & 8.0 & 7.5 & & 7.5 \\
\hline colony B & 4.5 & & 5.7 & 5.5 & 5.7 & & .7 & 4.3 & 4.3 & 4 & & 4.8 & 4.3 & 5.3 & & 5.3 \\
\hline Testing & \multicolumn{16}{|c|}{ Mean of 20 counts of the ants approaching each of the four presented numbers of elements } \\
\hline days & \multicolumn{4}{|c|}{3} & \multicolumn{4}{|c|}{6} & \multicolumn{4}{|c|}{9} & \multicolumn{4}{|c|}{12} \\
\hline $\mathrm{n}^{\circ}$ of elements & 1 & 1 & 2 & 3 & 1 & 1 & 2 & 3 & 1 & 1 & 2 & 3 & 1 & 1 & 2 & 3 \\
\hline colony A & 1.1 & 0.9 & 0.7 & 0.8 & 0.8 & 1.6 & 0.6 & 0.5 & 1.1 & 3.6 & 0.9 & 0.6 & 1.3 & 1.7 & 0.6 & 0.2 \\
\hline colony B & 0.9 & 1.4 & 0.4 & 0.2 & 2.5 & 2.1 & 0.8 & 0.3 & 1.0 & 2.2 & 0.7 & 0.5 & 1.6 & 2.9 & 1.0 & 0.3 \\
\hline
\end{tabular}

The elements used and their presentation to the ants are schematically shown in Figures 1 and 2, while photos of the experiment are given in Figure 3. Details and statistics are given in the text. Briefly, being trained to 1 and 1 elements not seen side by side, the ants mostly reacted to these two numbers, and far less to their sum (2) or wrong $\operatorname{sum}(3)$.

\subsection{Experiment II, on Colonies C and D; Training to 2 and 1 Elements; Testing to 2, 1, 3 and 4 Elements}

Numerical results are given in Table 2. During training, meanly 6.2 ants were at any time foraging in the vicinity of the two presented numbers of elements, having thus the possibility to see, memorize and add them.

After three training days, the ants did not essentially go towards the stand with 3 elements. On the contrary, they were more numerous in front of the stand bearing 2 elements (colonies $\mathrm{C}+\mathrm{D}=50$ ants) and of the stand bearing 1 element (colonies $\mathrm{C}+\mathrm{D}=55$ ants) (Figure 3, Experiment II). Summed by four over the experimental time, the numbers of ants counted in front of $2,1,3$ and 4 elements were: $11,9,7,8,15 ; 14,11,12,9,9 ; 9,7,5,5,2$; and 2, $8,5,2,4$ respectively. The smallest difference to be statistically analyzed was that between the stand with 2 
elements and that with 3 elements, and this difference was significant $(\mathrm{N}=5, \mathrm{~T}=15, \mathrm{P}=0.031)$. The ants reacted thus mostly to the elements they saw during training, and not to their correct and wrong sums. After six days of training, the ants essentially went to the stands bearing 2 and 1 elements. Summed by four, the numbers of ants seen in front of the stands with $2,1,3$ and 4 elements equaled $14,14,10,12,13 ; 16,11,14,13,16 ; 8,4,3,6,8 ; 4$, $3,1,2,3$ respectively. The smallest difference was between the ants seen in front of 1 element and those seen in front of 3 elements, and this smallest difference was significant $(\mathrm{N}=5, \mathrm{~T}=15, \mathrm{P}=0.031)$. The ants have thus again more reacted to 1 and 2 elements than to 3 and 4 ones. At day 9 , the same event occurred. The ants went essentially in front of the stands bearing 2 and 1 elements. Summed by four over the experimental time, the numbers of ants counted in front of $2,1,3$ and 4 elements equaled $13,8,8,14,12 ; 31,25,25,23,22 ; 9,5,3,5,5 ; 3,1,6,4,0$. The smallest difference was between the ants' response to 2 and to 3 elements ( $55 v s$ 27) (that between 1 and 3 elements was larger: $126 v s$ 27), and this smallest difference was significant $(\mathrm{N}=5, \mathrm{~T}=15, \mathrm{P}=0.031)$. The ants have thus responded more to the numbers of elements seen during training than to their correct and wrong sums. At day 12, the ants of the two colonies preferentially went to the stands bearing 2 and 1 elements, and less to those bearing 3 and 4 elements. Summed by four over the experimental time, the numbers of ants counted near 2, 1, 3 and 4 elements were $24,24,26,25,16 ; 26,27,27,31,25 ; 8,6,4,5,6 ; 2,4,5,4,5$ respectively. The smallest difference to be statistically examined was that between the numbers of ants corresponding to 2 elements and those corresponding to 3 elements, and this smallest difference was significant $(\mathrm{N}=5, \mathrm{~T}=15, \mathrm{P}=0.031)$. Thus, the ants reacted more to 2 and 1 elements consecutively seen during training than to their correct and wrong sums.

The proportions of ants having reacted to $2,1,3$ and 4 elements equaled at day $3: 31.6 \%, 35.4 \%$ (total $=67 \%$ ), $19.0 \%, 13.9 \%$; at day $6: 35.6 \%, 40.0 \%$ (total $=75 \%$ ), $16.7 \%, 7.8 \%$; at day $9: 25.0 \%, 56.3 \%($ total $=81 \%), 12.5 \%$, $6.3 \%$; and at day 12 : and $38.3 \%, 45.3 \%$ (total $=83.6 \%$ ), 9.7\%, 6.7\%. Therefore, in the course of their training time, the ants more and more reacted to the two numbers consecutively seen during training (from $67 \%$ to $83.6 \%$ ), and less and less to their correct and wrong sums.

A look to the entire experiment (Table 2) shows that the eight mean values obtained for the two numbers of elements presented during training were significantly higher than those obtained for the correct and the wrong sums of these two numbers ( $\mathrm{N}=8, \mathrm{~T}=36, \mathrm{P}=0.04$ or $\mathrm{N}=7, \mathrm{~T}=28, \mathrm{P}=0.008)$. The ants have thus continuously responded to the two consecutively seen numbers of elements and not to their sum.

Table 2. Results of experiment II conducted on colonies C and D for examining if ants could add $2+1$ elements never seen side by side

\begin{tabular}{|c|c|c|c|c|c|c|c|c|c|c|c|c|c|c|c|c|}
\hline \multirow{2}{*}{$\begin{array}{l}\text { Training } \\
\text { days }\end{array}$} & \multicolumn{16}{|c|}{ Mean of 6 daily counts of the ants present near the two presented numbers of elements } \\
\hline & 1 & & 2 & 3 & 4 & & 5 & 6 & 7 & r & & 9 & 10 & 11 & & 12 \\
\hline colony $\mathrm{C}$ & 6.3 & & 3.5 & 7.3 & 7.3 & & .7 & 6.3 & 4.7 & 4 & & 4.5 & 4.7 & 5.0 & & 4.7 \\
\hline colony D & 6.3 & & 3.7 & 7.7 & 7.5 & & 3 & 5.5 & 4.7 & 4 & & 10.0 & 9.3 & 9.3 & & 9.3 \\
\hline Testing & \multicolumn{16}{|c|}{ Mean of 20 counts of the ants approaching each of the four presented numbers of elements } \\
\hline days & \multicolumn{4}{|c|}{3} & \multicolumn{4}{|c|}{6} & \multicolumn{4}{|c|}{9} & \multicolumn{4}{|c|}{12} \\
\hline $\mathrm{n}^{\circ}$ of elements & 2 & 1 & 3 & 4 & 2 & 1 & 3 & 4 & 2 & 1 & 3 & 4 & 2 & 1 & 3 & 4 \\
\hline colony C & 1.7 & 1.3 & 1.1 & 0.2 & 2.0 & 1.2 & 0.3 & 0.3 & 1.1 & 3.0 & 0.6 & 0.0 & 3.6 & 3.0 & 1.0 & 0.6 \\
\hline colony D & 0.8 & 1.5 & 0.4 & 0.9 & 1.2 & 2.4 & 1.2 & 0.4 & 1.7 & 3.3 & 0.8 & 0.7 & 2.2 & 3.8 & 0.5 & 0.5 \\
\hline
\end{tabular}

The elements and their presentation to the ants are schematically explained in Figures 1 and 2; photos of the experiment are shown in Figure 3; details and statistics are given in the text. The ants reacted mostly to the 2 and 1 elements seen during training, and poorly to their sum (3) or wrong sum (4).

Twenty-four hours after the removal of the two stands set on the foraging areas to train the ants, the latter went on responding essentially to the two numbers seen during training. The mean number of ants counted in front of 2,1 , 3 and 4 elements equaled 2.3, 3.1, 1.0 and 0.2 for colony $\mathrm{C}$, as well as 1.4, 1.5, 0.1 and 0.5 for colony D respectively. Summed by four over the experimental time, the counted numbers were, for the two colonies, for 2, 1 , 3 , and 4 elements respectively, 20,16, 19, 16, 12;12,17, 17, 20, 23; 4, 4, 7, 3, 3; and 0, 3, 2, 7, 2. The ants continued thus to mostly react to 2 and 1 elements. Indeed, the smallest difference to be statistically examined was the difference between the ants' response to 2 elements and that to 3 elements, and this smallest difference was significant $(\mathrm{N}=5, \mathrm{~T}=15, \mathrm{P}=0.031)$. This recalled what occurred in the course of the study of the ants' ability in adding numbers of elements seen simultaneously (Cammaerts \& Cammaerts, 2019c): after having removed the stands with two numbers of elements used for training, the ants reacted essentially to these two numbers, and less to their correct sum. 


\subsection{Experiment III, on Colonies E and F; Training to 3 and 1 Elements; Testing to 3, 1, 4 and 5 Elements}

Numerical results are given in Table 3. During training, many ants were continuously walking all around the presented stands. They were meanly 7.7 in doing so. They could thus see many times, not at the same time, and never side by side, the two numbers of elements presented.

After 3 days of training, the ants went more towards the stands bearing 3 and 1 elements than towards the two other stands. Summed by four over the experimental time, the ants counted in front of 3, 1, 4 and 5 elements respectively equaled $13,14,16,17,10 ; 11,14,17,20,15 ; 1,2,7,7,3 ;$ and $0,0,1,2,2$. The smallest difference to be statistically examined was that between the ants' response to 3 elements and that to 4 elements, and this difference was significant $(\mathrm{N}=5, \mathrm{~T}=15, \mathrm{P}=0.031)$. The ants responded thus mostly to the two numbers of elements seen during training, and less to their sum or their sum plus 1 element. At day 6 , the ants were again more numerous near the stands bearing 3 and 1 elements than near those bearing 4 and 5 elements. Summed by four over the experimental time, the numbers of these ants counted near $3,1,4$ and 5 elements equaled $11,17,20,22$ and 20;18,21, 21, 18 and 19; 5, 4, 6, 7 and 6;1, 0, 0, 1 and 8 respectively. The smallest difference to be statistically examined was that between the ants counted near 3 elements and those counted near 4 elements, and this difference was significant ( $\mathrm{N}$ $=5, \mathrm{~T}=15, \mathrm{P}=0.031$ ). At day 9 , the ants went on responding essentially to 3 and 1 elements. Summed by four over the experimental time, the numbers of ants counted in front of $3,1,4$ and 5 elements were 14,24,26, 22 and $20 ; 18,23,19,23$ and $27 ; 3,4,3,4$ and $6 ; 0,1,0,0$ and 1 respectively. The smallest difference to be statistically analyzed was that between the ants' response to 1 element and that to 4 elements, and this difference was significant $(\mathrm{N}=5, \mathrm{~T}=15, \mathrm{P}=0.031)$. The ants reacted thus more to the two numbers seen during training than to their sum or their sum plus 1 element. After 12 training days, the ants once more reacted mostly to the two numbers of elements seen during training. Summed by four over the experimental time, the numbers of ants counted near 3 , 1,4 and 5 elements equaled 26, 29,29,23,21;12,16,18,16,13;2, 5, 0, 5, 6; and 1, 3, 2, 1, 0 respectively. The smallest difference to be statistically analyzed was that between the ants' response to 1 element and that to 4 elements, and this difference was significant $(\mathrm{N}=5, \mathrm{~T}=15, \mathrm{P}=0.031)$. The ants went thus more to 3 and 1 elements (seen during training) than to 4 and 5 elements.

The proportions of ants of the two colonies having responded to 3, 1,4 and 5 elements were at day $3: 40.9 \%, 45.0 \%$ $($ total $=85.9 \%), 11.7 \%$ and $2.3 \%$; at day $6: 40.0 \%, 43.3 \%$ (total $=83.1), 12.4 \%$ and $4.4 \%$; at day $9: 44.5 \%, 46.2 \%$ (total $=90.7 \%$ ), $8.4 \%$ and $0.8 \%$; at day $12: 56.1 \%, 32.9 \%$ (total $=89.0 \%$ ), $7.9 \%$ and $3.1 \%$. In the course of the 12 experimental days, there was a very slight increase of the ants' response to the two numbers seen during training.

Taking into account the eight mean values obtained for the two colonies at the four testing days (Table 3), it clearly appeared that the values corresponding to 3 as well as 1 elements statistically differed from those corresponding to 4 as well as 5 elements $(\mathrm{N}=8, \mathrm{~T}=36, \mathrm{P}=0.008)$. We can thus conclude that, when trained to numbers of elements never seen side by side at the same time, the ants did not react to the sum of these numbers, but largely reacted to the numbers seen during training.

Table 3. Results of experiment III performed on colonies $\mathrm{E}$ and $\mathrm{F}$ for examining if ants could add $3+1$ elements never seen side by side

\begin{tabular}{|c|c|c|c|c|c|c|c|c|c|c|c|c|c|c|c|c|}
\hline Training & \multicolumn{16}{|c|}{ Mean of 6 daily counts of the ants present near the two presented numbers of elements } \\
\hline days & 1 & & 2 & 3 & 4 & & 5 & 6 & 7 & $\varepsilon$ & & 9 & 10 & 11 & & 12 \\
\hline colony E & 7.3 & & 7.8 & 5.7 & 6.3 & & .7 & 7.5 & 7.5 & 6 & & 10.7 & 9.7 & 9.7 & & 8.8 \\
\hline colony $\mathrm{F}$ & 6.5 & & 7.2 & 6.5 & 7.3 & & .5 & 7.5 & 7.5 & 6 & & 9.2 & 8.5 & 8.5 & & 8.2 \\
\hline Testing & \multicolumn{16}{|c|}{ Mean of 20 counts of the ants approaching each of the four presented numbers of elements } \\
\hline days & \multicolumn{4}{|c|}{3} & \multicolumn{4}{|c|}{6} & \multicolumn{4}{|c|}{9} & \multicolumn{4}{|c|}{12} \\
\hline$n^{\circ}$ of elements & 3 & 1 & 4 & 5 & 3 & 1 & 4 & 5 & 3 & 1 & 4 & 5 & 3 & 1 & 4 & 5 \\
\hline colony E & 1.9 & 2.0 & 0.6 & 0.1 & 2.6 & 2.3 & 0.6 & 0.2 & 2.9 & 3.3 & 0.6 & 0.1 & 3.3 & 1.7 & 0.4 & 0.1 \\
\hline colony F & 1.7 & 1.9 & 0.5 & 0.2 & 1.9 & 2.6 & 0.8 & 0.4 & 2.4 & 2.2 & 0.5 & 0.0 & 3.1 & 2.1 & 0.6 & 0.3 \\
\hline
\end{tabular}

Details and statistics are given in the text; the elements presented to the ants, and their presentation, are schematically shown in Figures 1 and 2; three photos of the experiment are shown in Figure 3. The ants reacted more to the 3 and 1 elements they saw during training than to their sum (4) or to their sum plus 1 element (5).

Twenty-four hours after the removal of the stands used for training, the ants went on responding essentially to 3 and 1 elements. The mean numbers of ants counted near 3, 1, 4 and 5 elements were for colony E: 3.1, 2.5, 0.6 and 0.1, and for colony F: 2.0, 3.2, 0.5 and 0.2 respectively. Summed by four over the experimental time, the numbers of ants 
belonging to the two colonies seen near $3,1,4$ and 5 elements were $26,23,19,16,18 ; 26,20,19,22,25 ; 4,4,4,2,7$; and $0,0,2,1,3$ respectively. The smallest difference to be statistically examined was that between the ants' response to 3 elements and that to 4 elements, and this difference was significant $(\mathrm{N}=5, \mathrm{~T}=15, \mathrm{P}=0.031)$. Expressed in percentage, the ants' response to 3 and 1 elements totalized $89 \%$, and that to 4 and 5 elements totalized $11 \%$. Consequently, the ants have memorized the two cues seen during training. Such a memorization also occurred in the study of the ants' ability in 'adding' numbers seen side by side (Cammaerts \& Cammaerts, 2019c).

\subsection{Experiment IV, on Colonies $G$ and H; Training to 3 and 2 Elements; Testing to 3, 2, 5 and 6 Elements}

Numerical results are given in Table 4. While trained, the ants often came near the two presented stands and walked all around. Meanly 7.2 did so; the ants could thus see many times the two numbers of elements presented.

After three training days, the ants went more near the stands bearing 3 and 2 elements than near those bearing 5 and 6 elements. Summed by four over the experimental time, the numbers of ants counted in front of 3, 2, 5 and 6 elements were $21,21,26,20,18 ; 22,15,18,10,16 ; 8,3,6,7,3$; and $1,1,1,3,6$. The smallest difference to be statistically analyzed was that between the ants' response to 2 elements and that to 5 elements, and this smallest difference was significant $(\mathrm{N}=5, \mathrm{~T}=15, \mathrm{P}=0.031)$. The ants reacted thus mostly to the two numbers of elements seen during training, and poorly to their sum and their sum plus 1 element. At day 6 , the ants of the two colonies were more numerous near the stands bearing 3 and 2 elements than near those bearing 5 and 6 elements. Summed by four over the experimental time, the numbers of ants near 3,2, 5 and 6 elements equaled 20,25, 24, 24 and 24; $21,20,26,26$ and 26; 9, 9, 7, 2 and 5; 1, 4, 1, 0 and 0 respectively. The smallest difference to be examined was between the ants counted near 3 elements and those counted near 5 elements, and this difference was significant ( $\mathrm{N}$ $=5, \mathrm{~T}=15, \mathrm{P}=0.031$ ). Thus, the ants responded more to 3 and 2 elements than to 5 and 6 elements. At day 9 , the ants went on responding essentially to 3 and 2 elements. Summed by four over the experimental time, the numbers of ants counted in front of 3, 2, 5 and 6 elements were 28,33,32, 36 and 28; 23, 20, 23, 10 and 21; 6, 10, 8, 10 and $10 ; 0,0,2,0$ and 1 respectively. Thus, the ants reacted more to the two numbers seen during training than to their sum or their sum plus 1 element. At day 12, the ants once more reacted mostly to 3 and 2 elements. Summed by four over the experimental time, the numbers of ants counted near 3, 2, 5 and 6 elements equaled 24, 24, 25, 24, 28; $14,15,17,15,16 ; 1,2,4,4,6$; and $0,0,1,2,3$ respectively. The smallest difference to be statistically examined was that between the ants' response to 2 elements and their response to 5 elements, and this difference was significant $(\mathrm{N}=5, \mathrm{~T}=15, \mathrm{P}=0.031)$. The ants responded thus more to the two numbers seen during training than to their sum or their sum plus 1 element.

The proportions of ants of the two colonies having responded to 3,2, 5 and 6 elements in the course of the entire experiment were at day $3: 46.9 \%, 35.8 \%($ total $=82.7 \%), 11,9 \%$ and $5.3 \%$; at day $6: 42.5 \%, 43.3 \%($ total $=85.8 \%$ ), $11.6 \%$ and $2.2 \%$; at day $9: 50.6 \%, 34.2 \%$ (total $=84.8 \%), 14.2 \%$ and $1 \%$; at day $12: 55.6 \%, 34.2 \%$ (total $=89.8 \%$ ), $7.6 \%$ and $2.7 \%$. It appeared thus a very slight increase of the ants' response to the two numbers seen during training in the course of the 12 experimental days.

If the eight mean values, obtained at days 3, 6, 9 and 12 for the two colonies, are considered (Table 4), it appeared that the values corresponding to 3 and 2 elements were statistically larger than those corresponding to 5 and 6 elements $(\mathrm{N}=8, \mathrm{~T}=36, \mathrm{P}=0.008)$. Consequently, when trained to numbers of elements never seen side by side, the ants did not react to their sum, but largely responded to the two seen numbers.

Table 4. Results of experiment IV performed on colonies $\mathrm{G}$ and $\mathrm{H}$ for examining if ants could add $3+2$ elements never seen side by side

\begin{tabular}{|c|c|c|c|c|c|c|c|c|c|c|c|c|c|c|c|c|}
\hline \multirow{2}{*}{$\begin{array}{l}\text { Training } \\
\text { days }\end{array}$} & \multicolumn{16}{|c|}{ Mean of 6 daily counts of the ants present near the two presented numbers of elements } \\
\hline & 1 & & 2 & 3 & 4 & & 5 & 6 & 7 & senta & & 9 & 10 & 11 & & 12 \\
\hline colony G & 9.2 & & 9.5 & 9.2 & 9.7 & & .7 & 6.7 & 7.2 & 7 & & 6.3 & 6.2 & 7.5 & & 7.3 \\
\hline colony $\mathrm{H}$ & 5.5 & & 6.5 & 6.7 & 6.3 & & .7 & 6.3 & 7.2 & 6 & & 6.3 & 6.5 & 6.7 & & 6.2 \\
\hline Testing & \multicolumn{16}{|c|}{ Mean of 20 counts of the ants approaching each of the four presented numbers of elements } \\
\hline days & \multicolumn{4}{|c|}{3} & \multicolumn{4}{|c|}{6} & \multicolumn{4}{|c|}{9} & \multicolumn{4}{|c|}{12} \\
\hline $\mathrm{n}^{\circ}$ of elements & 3 & 2 & 5 & 6 & 3 & 2 & 5 & 6 & 3 & 2 & 5 & 6 & 3 & 2 & 5 & 6 \\
\hline colony G & 3.7 & 1.7 & 0.9 & 0.3 & 3.6 & 3.5 & 1.1 & 0.0 & 1.1 & 3.0 & 0.6 & 0.0 & 3.6 & 3.0 & 1.0 & 0.6 \\
\hline colony $\mathrm{H}$ & 1.6 & 2.4 & 0.5 & 0.3 & 2.3 & 2.5 & 0.6 & 0.3 & 3.8 & 2.3 & 1.0 & 0.1 & 3.2 & 2.0 & 0.5 & 0.3 \\
\hline
\end{tabular}

Details and statistics are given in the text; the elements presented to the ants, and their presentation, are schematically shown in Figures 1 and 2; three photos of the experiment are shown in Figure 3. The ants reacted more to the 3 and 2 elements they saw during training than to their sum (5) or to their sum plus 1 element (6). 
Twenty-four hours after the removal of the two stands set on the ants' foraging areas, the ants continued to respond mostly to 3 and 2 elements. The mean numbers of ants counted near 3, 2, 5 and 6 elements equaled for colony G: 5.4, 4.6, 0.7 and 0.8 , and for colony H: 5.3, 3.3, 0.8 and 0.3 respectively. Summed by four over the experimental time, the numbers of ants of the two colonies approaching $3,2,5$ and 6 elements were $36,41,41,45,50 ; 35,29,26$, 36,$30 ; 6,4,7,5,7$; and 5, 3, 1, 6, 6 respectively. The smallest difference to be statistically examined was that between the ants' response to 2 elements and that to 5 elements, and this difference was significant $(\mathrm{N}=5, \mathrm{~T}=15$, $\mathrm{P}=0.031$ ). Expressed in percentages, the ants' response to 3 and 2 elements totalized $88 \%$, and that to 5 and 6 elements totalized $12 \%$. Thus, the ants have retained what they saw during training. Such a memorization of the numbers seen during training also occurred during the study of the ants' ability in 'adding' numbers seen side by side, (Cammaerts \& Cammaerts, 2019c).

\subsection{Comparison of Experiments I to IV}

During each experiment, the ants clearly reacted to the two numbers of elements seen during training, and failed in reacting to their sum or their sum plus one element (Figure 4). This was consistent between the four conducted experiments, and fully differed from what occurred when the numbers of elements were presented side by side, at the same time to the ants: the ants then essentially reacted to the sum of the two presented numbers (Cammaerts \& Cammaerts, 2019c).

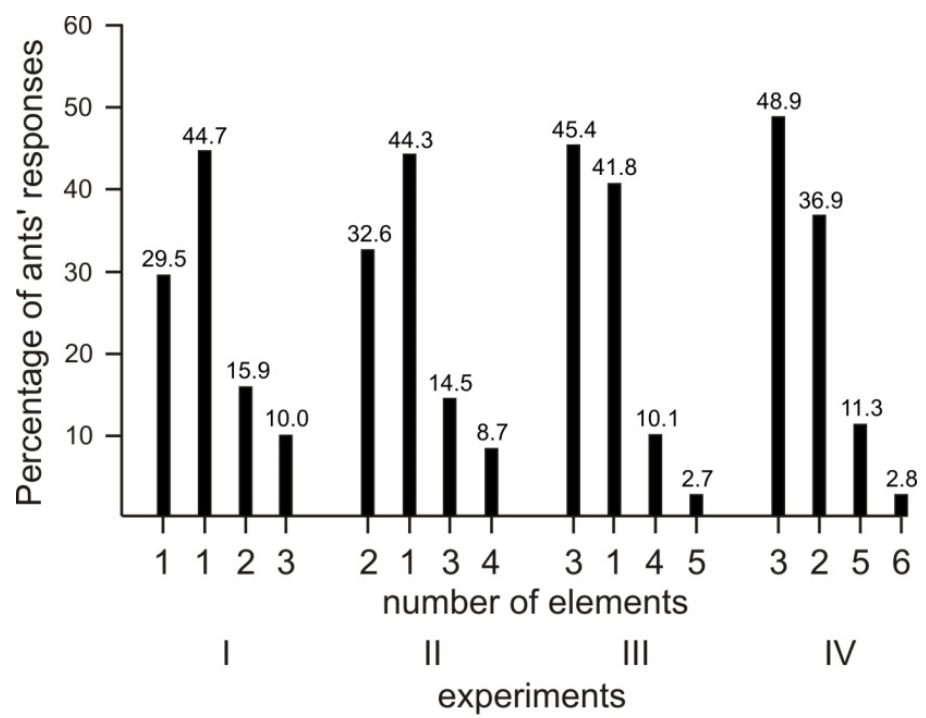

Figure 4. Proportions of ants responding to two numbers of elements consecutively seen during training (the two first numbers for each experiment, i.e. 1,$1 ; 2,1 ; 3,1$; and 3,2), and to the sum and the sum plus 1 element of these numbers (the two last numbers for each experiment, i.e. 2,$3 ; 3,4 ; 4,5$; and 5, 6)

The ants responded to the numbers of elements they saw consecutively while being trained, and not to their sum or their sum plus 1 element, contrary to what they did when trained to numbers seen side by side (Cammaerts \& Cammaerts, 2019c). They somewhat gave more accurately such a response when trained to 3 and 1 elements or to 3 and 2 elements (experiments III and IV) than when trained to 1 and 1 elements or to 2 and 1 elements (experiments I and II). All this allows concluding that ants have a concrete and not an abstract notion of numbers and of adding.

The results of experiments I and II on one side, and of experiments III and IV on the other side are very similar to one another. A small difference appeared between the results of experiments I and II on one hand and those of experiments III and IV on the other hand: in the course of the two latter experiments, the ants more accurately reacted to the numbers of elements they saw during training. In details, the proportion of ants responding to the numbers seen during training and that of ants responding to the sum and the sum plus 1 element of these numbers respectively equaled for experiment I: $73.7 \%$ and $25.9 \%$, for experiment II: $76.7 \%$ and $23.2 \%$, for experiment III: $87.2 \%$ and $12.8 \%$, for experiment IV: $85.8 \%$ and $14.1 \%$. Such a difference between experiments relative to 1 to 3 elements and experiments relative to 4 and 5 elements also appeared during the work on the ants' ability in 'adding' numbers seen side by side (Cammaerts \& Cammaerts, 2019c). This may be due to the fact that ants have a concrete and not an abstract concept of numbers and adding. 


\section{Discussion}

During the present work, the ants saw two numbers of identical elements not presented side by side, but making an angle of $270^{\circ}$ between them. After training, the ants responded to the two numbers of elements they saw, and not to their sum, better when experimented with 4 and 5 elements than with 1 to 3 elements. On the contrary, when trained to two numbers of elements presented side by side, the ants responded to their correct sum, and responded in this way somewhat less well for 4 and 5 elements than for 1 to 3 elements (Cammaerts \& Cammaerts, 2019c). Consequently, the ants present a visual, concrete notion of summing elements, and not an abstract mathematical notion of adding. They memorized numbers seen consecutively, but having not seen them one aside the other, they failed in responding to their sum. Compared to what occurs when human children learn to add numbers, the ants 'add' numbers like do human children just at the start of their learning, when they are presented with concrete numbers set side by side, or more exactly under a presentation making their learning easier. After some time, human children progressively, in two or three steps, learn to add numbers without concretely seeing them. Note that the learning of counting and adding is independent of that of writing and reading (Barth, La Mont, Lipton, \& Spelke, 2005). Some evolved vertebrates seem to be able to add numbers of elements even if not seeing them exactly side by side at the same time. This ability exists for instance in some fishes, frogs, birds and monkeys (see the introduction section). However, as this ability is very limited, the experimented animals have probably only a concrete notion of the numbers.

In their chapter 'Counting in animals and humans', Gelman and Cordes (2001) detailed our here above idea (i.e. animals have only a concrete notion of the numbers). The authors explain that "the ability to count, to add etc... can be considered as being a too abstract capacity for animals (birds, dogs, apes, bees ...). The numerical cognition depends on the development of abstract reasoning structures". Here are two examples of such a lack of abstract mathematical concept. Working on bees, Dacke and Srinivasan (2008) showed that these social insects could recognize up to four encountered landmarks (or other objects), and use this ability while foraging. The bees must see one after the other the four cues; they must be concretely trained to them, for being able to acquire the notion of '4'. In 1931, Kuroda investigated the ability of a monkey to discriminate between 1 and 2 sounds, then between 1 and 3 sounds. The first discrimination was obtained in 700 trials; attempts to obtain the second one led to the lost of the first one. The author explained such a failure by the requirement of an 'absolute property of number' (an abstract concept of number) for discriminating two numbers of sound (of course not perceived at the same time).

Though they could not react to the sum of numbers of elements not seen side by side (present work), the ants appear to have a concrete notion of 'nothing', of 'zero' elements (Cammaerts \& Cammaerts, 2019a, b). Our next aim will be to examine 1) if the ants can locate the 'zero' (their notion of 'zero') at the end of a decreasing series of elements, as well as at the start of an increasing series of elements, and 2) if they can subtract a number of elements from another larger number of elements.

To conclude, the works made on the ants' notion of numbers, zero, and addition allow stating that these insects have a concrete notion of numbers (i.e. they can distinguish different numbers), a concrete notion of zero (they can estimate that there is 'nothing', no element), and can 'add' small numbers according to a concrete manner, i.e. can associate numbers of elements seen together side by side during training. Conditional to potential future discoveries, it can thus be stated that the ants (at least the species M. sabuleti) have not an abstract notion of mathematical concepts. The frontiers, the limits of their cognitive abilities may thus be the transition to abstraction.

\section{Conflict of interest}

We affirm having no conflict of interest concerning the ants' or any other animals' ability in adding numbers of elements. We also affirm having maintained the ants in the best possible conditions.

\section{References}

Agrillo, C., Dadda, M., Serena, G., \& Bisazza, A. (2009). Use of number by fish. PLoS One, 4(3), e4786.

Agrillo, C., Miletto Petrazzini, M. E., \& Bisazza, A. (2017). Numerical abilities in fish: A methodological review. Behavioural Processes, 141(Pt 2), 161-171.

Barth, H., La Mont, K., Lipton, J., \& Spelke, E. S. (2005). Abstract number and arithmetic in preschool children. PNAS, 102(39), 14116-14121.

Beran, M. J., Perdue, B. M., \& Evans, T. A. (2015). Monkey mathematical abilities. In R. C. Kadosh, \& A. Dowker (Eds.), The Oxford handbook of numerical cognition. Oxford: Oxford University Press.

Cammaerts, M. C. (2008). Visual discrimination of cues differing as for their number of elements, their shape or their orientation, by the ant Myrmica sabuleti. Biologia, 63, 1169-1180. 
Cammaerts, M. C., \& Cammaerts, R. (2019a). Ants are at the first stage of the notion of zero. International Journal of Biology, 11(1), 54-65.

Cammaerts, M. C., \& Cammaerts, R. (2019b). Ants' notion of zero through the perception of the absence of an odor. International Journal of Biology, 11(2), 1-12.

Cammaerts, M. C., \& Cammaerts, R. (2019c). Ants' capability of adding numbers of identical elements. International Journal of Biology, 11(3), 25-36.

Dacke, M., \& Srinivasan, M. V. (2008). Evidence for counting in insects. Animal Cognition, 11(4), 683-689. Retrieved from https://portal.research.lu.se/portal/en/...for...in.../export.html

Ditz, H. M., \& Nieder, A. (2015). Neurons selective to the number of visual items in the corvid songbird endbrain. PNAS June 23, 112(25), 7827-7832.

Ditz, H. M., \& Nieder, A. (2016). Numerosity representations in crows obey the Weber-Fechner law. Proceedings of the Royal Society B, 283, 1-9. Retrieved from http://rspb.royalsocietypublishing.org/

Fuson, K. C. (1988). Children's counting and concepts of number. New York: Springer-Verlag. Retrieved from https://www.springer.com/la/book/9781461283355

Garland, A., \& Low, J. (2014). Addition and subtraction in wild New Zealand robins. Behavioural Processes, 109, 103-110.

Gelman, R., \& Cordes, S. (2001). Counting in animals and humans. In E. Dupoux (Ed.), Language, brain, and cognitive development: Essays in honor of Jacques Mehler (pp. 279-301). Cambridge, MA, US: The MIT Press.

Hoag, H. (2003). Salamanders can do maths. Nature 3 May.

Howard, S. R., Avarguès-Weber, A., Garcia, J. E., Greentree, A. D., \& Dyer, A. G. (2019). Numerical cognition in honeybees enables addition and subtraction. Cognitive Neuroscience, 5, 1-6. Retrieved from http://advances.sciencemag.org/

Kuroda, R. (1931). On the counting ability of a monkey (Macacus cynomolgus). Journal of Comparative Psychology, 12(2), 171-180.

Pepperberg, I. M. (2006) Grey parrot numerical competence: A review. Animal Cognition, 9(4), 377-391. Retrieved from http://psycnet.apa.org/record/2007-07451-012

Rodriguez, R. L., Briceno, R. D., Briceno-Aguilar, E., \& Höbel, G. (2015). Nephila clavipes spiders (Araneae: Nephilidae) keep track of captures prey counts: Testing for a sense of numerosity in an orb-weaver. Animal Cognition, 18(1), 307-314.

Rugani, R., Vallortigara, G., Priftis, K., \& Regolin, L. (2015). Number-space mapping in the newborn chick resembles humans' mental number line. Science, 347(6221), 534-536.

Siegel, S., \& Castellan, N. J. (1989). Nonparametric statistics for the behavioural sciences. Singapore, McGraw-Hill Book Company. Retrieved from https://www.amazon.com/Sidney-Siegel...Statistics.../B00 8W DIR6

\section{Copyrights}

Copyright for this article is retained by the author(s), with first publication rights granted to the journal.

This is an open-access article distributed under the terms and conditions of the Creative Commons Attribution license (http://creativecommons.org/licenses/by/4.0/). 